\title{
Conservative surgery and the total thyroidectomy in well-Differentiated thyroid cancer
}

\begin{abstract}
Introduction: There is an actual consensus regarding the Importance of Categorizing by risk groups Patients in order to select the most accurate treatment well-Differentiated regarding thyroid cancer.
\end{abstract}

Objectives: Total to describe the results of conservative surgery, as well as thyroidectomy performed on Patients with Differentiated thyroid cancer well.

Methods: A descriptive research of a longitudinal study was performed between 1995 and 2016 at the General Surgery Service of the Hospital Hermanos Ameijeiras. The main variables used were demographic, tumor related, surgery type and result type.

Results: A Total of 183 Patients Were included in the research. The most used type surgery was the Total thyroidectomy (79.2\%). Individuals with ages 41 and 50 years between were predominant $(30.6 \%)$. Were more conservative technics frequently performed in the group of Patients between 19 and 40 years old? For older than 40 years Patients Total thyroidectomy was the more frequent. Female gender was the biggest group (82.5\%). Predominant tumor size was in the range from $1 \mathrm{~cm}$ to $2.9 \mathrm{~cm}$. In the low risk group 3062 Total conservative surgeries and thyroidectomies were performed. Conservative surgeries HAD no complications, recurrence or mortality. Total thyroidectomy regarding $3.3 \%$ of the Patients Suffered transitory dysphonia, $2.2 \%$ and 0.5 presented transitory hypoparathyroidism $\%$ permanent.

Conclusion: Conservative surgery HAD no complications, recurrence or mortality. Total thyroidectomy ADH them.

Keywords: well-differentiated cancer, risk groups, conservative surgery, the total thyroidectomy
Volume 7 Issue 6 - 2018

\author{
Ramón González Fernández,' Ahmed Llapur \\ Gónzalez, ${ }^{2}$ Domingo Pérez González ${ }^{3}$ \\ 'Department of Second Degree Specialist in General Surgery, \\ University Hospital Hermanos Ameijeiras, Cuba \\ ${ }^{2}$ Department of First Degree Specialist in General Medicine and \\ General Surgery, Cuba \\ ${ }^{3}$ Department of Second Degree Specialist in General Surgery, \\ University Hospital Hermanos Ameijeiras, Cuba
}

Correspondence: Ramón González Fernández, Department of Second Degree Specialist in General Surgery, University Hospital Hermanos Ameijeiras, Havana, Cuba, Email rglaz@infomed.sld.cu

Received: August 10, 2018 | Published: November 22, 2018

\section{Introduction}

Despite being the endocrine neoplasia most common thyroid cancer, it occupies only about $2 \%$ of all cancers, is more common in women than in men, ratio of 3 to 1 and in most cases patients between 25 and 65 years. Well-differentiated tumors (papillary and follicular) are usually curables. ${ }^{1}$ The little aggressive biological behavior of well-differentiated tumors, led in the early 80 s of last century, there is and Cadi, started talking of factors forecasts in this variety of tumor and introduced different scales for evaluation, assigning patients into two groups: high and low risk. Thus the AGES, AMES, mace, and GAMES DAMES appears. All based their assessment on factors related to the patient (age and sex) and the tumor (size, extent, degree of differentiation, metastasis behavior of DNA, resection), according to the result of this assessment and according to group which is included the patient, less extensive surgical techniques proposed for low risk. ${ }^{1}$ Age, degree of differentiation, the extent and size of the tumor play an important role in deciding on treatment, which everyone agrees is surgical excision, but opinions vary when determining the extent of resection for effective treatment, hence "to be adjusted surgical techniques according to each patient carcinoma", this is achieved by the proper staging and defining groups risk. ${ }^{2}$

The controversy around what is best for thyroid cancer evidence that there are no conclusive results showing that a treatment is better than another, especially in the therapeutic treatment of differentiated carcinoma. All researchers agree that the surgical treatment of differentiated thyroid cancer is the most effective, and most discussed today is the extent of resection, especially if the injury is confined to a single lobe. Criteria justifying conservative surgery are based on the results of histological studies of healthy lobe of patients with total thyroidectomy, in studies of necropsies performed to deceased from other causes that reveal the high frequency of carcinoma located thyroid one lobe, and lower incidence of recurrence in cases where hemithyroidectomy with isthmectomy is performed. Several authors refer to the complications that often occur in patients who underwent thyroidectomy is applied total. ${ }^{3,4}$ The aim of this paper is to describe the results of conservative surgery and performed total thyroidectomy patients with well-differentiated thyroid cancer in the Clinical Surgical Teaching Hospital Hermanos Ameijeiras.

\section{Method}

An investigation of descriptive Slitting was performed in the period January 1995 to January 2016, in the service of General Surgery Hospital Hermanos Ameijeiras. The universe of study was given by all patients undergoing thyroid disease ( 864 patients) both benign and malignant, in the Hermanos Ameijeiras Hospital. The sample was made up of all patients with well-differentiated thyroid cancer (183 patients) met the criteria for research. 


\section{Inclusion criteria}

a) Patients with well-differentiated thyroid cancer diagnosed and categorized in the period January 1995 to January 2016.

b) Patients operated by the group of thyroid surgery in our center.

\section{Exclusion criteria}

a) Failure to attend follow-up consultation.

b) Refusal to participate in research.

\section{Technical and statistical procedures}

Database of patients diagnosed with well-differentiated thyroid cancer was revised, diagnosed and followed by chief surgeon of the line of development of this entity in the Ameijeiras Brothers Hospital from January 1995 to January 2016. The statistical package was used SPSS. PC, version 20.0. Summary measures (absolute and relative frequencies expressed in percentages, for qualitative variables) were determined. Crosstabs two inputs were prepared and the association between variables in two categories was assessed by analyzing the Fisher exact test for variables with more than two categories analysis was performed using the chi-square test, considering a significant result a probability value associated with any evidence of 0.05 .

\section{Results}

The Predominant age group was 41 to 50 years with 56 patients
$(30.6 \%)$. In the age group 19 to 40 years there was a higher percentage of conservative techniques in relation to total thyroidectomy, while those over 40 years most frequently performed total thyroidectomy (Table 1).

Table 2 shows the distribution of patients according to tumor size and type is surgical techniques performed. In 119 patients tumor size it was between $1 \mathrm{~cm}$ and $2.9 \mathrm{~cm}(65 \%)$, performing in this measuring range $64.1 \%$ (93 patients) of total thyroidectomy and $68.4 \%$ (26 patients) of conservative interventions. The tumors were histologically papillary carcinoma with 175 patients $(95.6 \%)$, performing in such histological 141 total thyroidectomy $(97.2 \%)$ and 34 conservative surgeries (89.5\%); however, conservative surgery was performed in half of the cases of follicular variety (Table 3 ).

Table 4 present the results of the type of operation selected according to risk groups. In the high risk group, there was no patient to perform conservative surgery performed 83 total thyroidectomy. Associating with 24 cases $(28.9 \%)$ with radicals dissections neck classical or modified as indicated. In the low risk group and 38 conservative techniques they were performed 62 total thyroidectomy. The patients who underwent conservative surgery had no complications, recurrence, or mortality, while the total thyroidectomy 6 patients $(3.3 \%)$ had transient dysphonia, 4 patients $(2.2 \%)$ had transient hypoparathyroidism, a patient $(0.5 \%)$ had permanent hypoparathyroidism. As recurrence 7 patients $(3.8 \%)$ had local recurrence of the disease and 4 patients (2.2\%) died (Table 5).

Table I Distribution of patients by age group and type of surgery

\begin{tabular}{llll}
\hline $\begin{array}{l}\text { Age group } \\
(\text { years })\end{array}$ & $\begin{array}{l}\text { conservative surgery } \\
\mathbf{n}(\%)\end{array}$ & $\begin{array}{l}\text { Total thyroidectomy } \\
\mathbf{n}(\%)\end{array}$ & $\begin{array}{l}\text { Total } \\
\mathbf{n}(\%)\end{array}$ \\
\hline Less than 20 & $4(10.5)$ & $2(1.4)$ & $6(3.3)$ \\
$21-30$ & $12(31.6)$ & $13(9.1)$ & $25(13.7)$ \\
$31-40$ & $9(7.23)$ & $16(11.0)$ & $25(13.7)$ \\
$41-50$ & $10(26.3)$ & $46(31.7)$ & $56(30.6)$ \\
$51-60$ & $2(5.3)$ & $34(23.4)$ & $36(19.6)$ \\
60 & $1(2.6)$ & $34(23.4)$ & $35(19.1)$ \\
Total & $38(100)$ & $145(100)$ & $183(100)$ \\
\hline
\end{tabular}

Table 2 Distribution of patients by tumor size and type of surgery

\begin{tabular}{llll}
\hline Tumor size (cm) & Conservative surgery $\mathbf{n}(\mathbf{\%})$ & Thyroidectomy total n(5) & Total n(\%) \\
\hline$<1$ & $9(7.23)$ & $14(9.7)$ & $23(12.6)$ \\
$1-2.9$ & $26(68.4)$ & $93(64.1)$ & $119(65.0)$ \\
$3-4.9$ & $3(7.9)$ & $26(17.9)$ & $29(15.8)$ \\
$>5$ & - & $12(8.3)$ & $12(6.6)$ \\
Total & $38(100)$ & $145(100)$ & $183(100)$ \\
\hline
\end{tabular}


Table 3 Distribution by histologic type and surgical intervention

\begin{tabular}{llll}
\hline Histological type & $\begin{array}{l}\text { Conservative surgery } \\
\mathbf{n ( \% )}\end{array}$ & $\begin{array}{l}\text { Total thyroidectomy } \\
\mathbf{n ( \% )}\end{array}$ & $\begin{array}{l}\text { Total } \\
\mathbf{n}(\%)\end{array}$ \\
\hline papillary carcinoma & $34(89.5)$ & $141(97.2)$ & $175(95.6)$ \\
follicular carcinoma & $4(10.5)$ & $4(2.8)$ & $8(4.4)$ \\
Total & $38(100)$ & $145(100)$ & $183(100)$ \\
\hline
\end{tabular}

Table 4 Risk groups and type of surgery

\begin{tabular}{|c|c|c|c|c|c|}
\hline \multirow{2}{*}{$\begin{array}{l}\text { Risk } \\
\text { groups }\end{array}$} & \multicolumn{2}{|c|}{$\begin{array}{l}\text { Conservative surgery Hemit+T Istmec almost } \\
\text { Total }\end{array}$} & \multicolumn{2}{|c|}{$\begin{array}{l}\text { Total thyroidectomy Thyroid Total TT+Vac } \\
\text { gang }\end{array}$} & \multirow{2}{*}{$\begin{array}{l}\text { Total } \\
\text { n(\%) }\end{array}$} \\
\hline & n(\%) & $\mathbf{n}(\%)$ & $n(\%)$ & n(\%) & \\
\hline High risk & - & - & $59(71.1)$ & $24(28.9)$ & $83(45.4)$ \\
\hline Low risk & $10(10)$ & $28(28)$ & $62(62)$ & - & $100(54.6)$ \\
\hline Total & $10(5.5)$ & $28(15.3)$ & $121(66.1)$ & $24(13.1)$ & $183(100)$ \\
\hline
\end{tabular}

Table 5 Relationship between surgical techniques and complications, recurrence and mortality

\begin{tabular}{llllll}
\hline Type of surgery & Complications & & & Recurrence & Mortality \\
& dysphonia Hipoparat & & Hipoparat \\
& transitory transient & & permanent & & \\
& $\mathbf{n}(\%)$ & $\mathbf{n}(\%)$ & $\mathbf{n}(\%)$ & $\mathbf{n}(\%)$ & $\mathbf{n}(\%)$ \\
\hline Total thyroidectomy & $6(3.3)$ & $4(2.2)$ & I $0.5 \%$ & $7(3.8)$ & $4(2.2)$ \\
\hline
\end{tabular}

\section{Discussion}

Surgical excision is accepted as the mainstay of treatment of differentiated carcinoma of tiroides. ${ }^{5,6}$ Surgical options include the isthmectomy hemithyroidectomy and almost total thyroidectomy, as conservative techniques and total thyroidectomy with or without lymphadenectomy cervical. ${ }^{7,8}$ To decide the surgery to be performed must assess the extent of the primary tumor (local behavior) and the presence of metastasis in cervical lymph nodes (regional behavior) and the extent to distancia. ${ }^{9}$ In this research conserving surgery is performed in patients at low risk women under 45 and men under 40 years, with size smaller tumor $2.5 \mathrm{~cm}$, which does not have capsular, vascular or lymphatic invasion, tracing a nonaggressive lobe histologic and treatment is indicated by levothyroxine suppressive dose all patients in monitoring, semi-based physical examination, thyroglobulin, TSH, T4. If necessary ultrasound and CAAF. The authors of this research advocate this type of treatment for patients with well-differentiated cancer, previously categorized into risk groups, which is a prerequisite for good results, and adjust the treatment to each patient carcinoma. Age appears to be one of the most important prognostic factors is vital for proper staging, besides age in women 50 and men over 40 years is one of the elements to classify them into risk groups, which is crucial to the when bearings in surgical techniques to be realizar. ${ }^{10,11}$

In an investigation by Gómez $\mathrm{KA}^{15}$ presentation the average age was 43.02 years which is consistent with this investigación. ${ }^{12-15}$ Guidelines from the National Comprehensive Cancer Network (NCCN) 2010 hemithyroidectomy raise conducting more isthmectomy as procedure initial surgical patients with well-differentiated thyroid cancer, aged between 15 and 45 , tumor size up to $4 \mathrm{~cm}$, no history of radiation in head and neck, or cervical lymph node metastasis, or distancia. ${ }^{12}$

ATA Guides (American Thyroid Association) 2015, recommended for patients Hemithyroidectomy $1 \mathrm{~cm}$ lower thyroid cancer. They also recommended both conservative interventions totals in tumors from 1 to $4 \mathrm{~cm}$ having no extrathyroidal or clinical evidence of cervical lymph metastásicos. ${ }^{13}$

According to the guidelines of the British Society of Thyroid 2014 total thyroidectomy in patients with tumor larger than $4 \mathrm{~cm}$ in diameter, or tumors of any size, but multifocal, multicentric, with extrathyroid extension or lymph node or distant metastases is recommended; and the isthmectomy hemithyroidectomy in patients with tumor less than $4 \mathrm{~cm}$ without the risk factors listed above. In patients with tumors between $1 \mathrm{~cm}$ and $4 \mathrm{~cm}$ and risk factors (age over 45 , capsular invasion, vascular and nodal or distant metastases) total thyroidectomy is recommended. ${ }^{14}$

In this study the tumors were histologically papillary carcinoma (95.6\%). Gómez $\mathrm{KA}^{15}$ et al, in their study concluded that the most frequent presentation is the papillary histic $70 \%$, while JR Lucena Olavarrieta in a sample of 85 patients, found 33-year evolution papillary carcinoma in $64.7 \%$ and $17.64 \%$ follicular. ${ }^{15-19}$ In this study the low-risk group represented $54.6 \%$ of cases, we do not make conservative surgery in high-risk group. Total thyroidectomy was the most used intervention. Classification by risk groups is important, especially in determining the extent of surgical resection should be performed conservative surgery alone in the low-risk group, hence the importance of categorizing risk groups prior to the selection of the surgical techniques. Blake-ranking Cady was used in this work 
to classify patients into groups of high risk and low risk. In the present study conserving surgery had no complications, recurrence or mortality, while total surgery had low rate of permanent complications Hypoparathyroidism $0.5 \%$. 3.8\% local recurrence of the disease, all in advanced stages of it, belonging to high-risk group was presented. This result may be because an appropriate categorization risk group and criteria was performed for conserving surgery, in addition to focusing the treatment individually and adjusted to carcinoma of each patient, which shows that has been effective for the good results so is not coinciding with the literature reviewed where higher recurrence observed in conservative surgery group. According F. Vaisman reported a recurrence of $4.2 \%$ in patients diagnosed with cancer papillary tiroides. ${ }^{20}$ An analysis by Bilimoria et al found an increase of recurrences in patients treated only with hemithyroidectomy when tumors were greater than $1 \mathrm{~cm} .^{21}$

Mazzaferri THE He has shown that total thyroidectomy is associated with a lower rate of recurrence and mortality compared hemitiroidectomía. ${ }^{21,22}$ In a study published by Pardal Refoyo JL report transient hypoparathyroidism $5 \%$ recurrent paralysis $1.2 \%{ }^{23}$ In this study $2.2 \%$ of patients died, all the high-risk group with locally advanced disease and distant metastases. In a study by David LópezBru and colleagues at the University of Alicante General Hospital in patients with differentiated thyroid cancer with 30 years of follow up, it was concluded that 1 in 8 people die in the course of 9 years seguimiento. ${ }^{1}$

\section{Conclusion}

Conservative surgery was performed more frequently in women, under 40 years, tumor size from 1 to $2.9 \mathrm{~cm}$, located in one lobe, in papillary carcinoma, low-risk group tumor and no complications, recurrence or mortality.

Total thyroidectomy was more frequent in females, aged 41, tumor size from 1 to $2.9 \mathrm{~cm}$, located in the right lobe, in papillary carcinoma, high-risk patients and had a low complication rate, recurrence and mortality.

\section{Acknowledgements}

None.

\section{Conflicts of interest}

The authors declare that there is no conflict of interest.

\section{References}

1. González Fernández R, Vidal God, Infante Amoros JM, et al. Protocol diagnosis and treatment of thyroid cancer. Rev Cubana Cir. 2004;43(2):34-93.

2. Ortega JA Peñate. Extended surgical treatment of thyroid nodule based on fine needle aspiration cytology. Cuba: Medical University of Matanzas publishers; 2009. $151 \mathrm{p}$.

3. Pérez Morales JM, Triana Alonso P, Núñez López MB. Conservative surgery in differentiated thyroid cancer. Medicentro. 2004;10 (4):612621.

4. Hurtado Lopez LM. Extension surgery well differentiated thyroid cancer and its relation to surgical morbidity. Cir Cir. 2007;75(2):71-74.

5. Davies L, Welch HG. Increasing incidence of thyroid cancer in the United States, 1973-2002. JAMA. 2006;295(18):2164-2167.
6. Pacini F, Schlumberger M, Dralle H. European taskforce thyroid cancer. European Consensus for the Management of Patients With Differentiated thyroid carcinoma of the follicular epithelium. Eur $J$ Endocrinol. 2006;154(6):787-803.

7. Townsend CM, Beauchamp RD, Evers BM, et al. Sabiston Surgery Treaty. 19th ed. Spain: Elsevier; 2013. 2176 p.

8. Shaha J, T Loree, Dharker DE. Strong lobectomy versus total thyroidectomy for Differentiated carcinoma of the thyroid: a matchedpair analysis. Am J Surg. 1993;166(4):331-335.

9. Haugen BR, Alexander EK, Bible KC. American Thyroid Association management guidelines for adult Patients With Differentiated thyroid nodules and thyroid cancer: the American Thyroid Association Guidelines Task Force on Differentiated thyroid nodules and thyroid cancer. Thyroid. 2015;26(1): 1-133.

10. Gonzalez H, Mosso L, Cruz F, et al. Papillary thyroid carcinoma: impact of pre-operative staging of the neck. Annl Meet Endocrine Soc. 2006;133(12):1258-1262.

11. Carling T, Udelsman R. Thyroid tumors. In: DeVita VT, Lawrence TS, Rosenberg SA. Cancer: Principles and Practice of Oncology. 9th ed. Philadelphia: Lippincott Williams \& Wilkins; 2011.58 p.

12. American Cancer Society. Cancer Facts and Figures. Atlanta: American Cancer Society; 2015. 56 p.

13. Estomba C, Araujo Da Costa CM Melendez AS García Rivera Schmitz JM, Alonso Párraga T. Diagnostic tests for thyroid disease. Rev Port Otorrinolaringol Cir Cervicofac. 2017;51:167-171.

14. López Bru D, Bru Palazón A, Manuel de la Rosa Folgado D, et al. Scoring system for mortality In Patients diagnosed with AND Treated Differentiated thyroid carcinoma surgically for with a 20-year follow-up. PLoS One. 2015;10:0128620.

15. Gomez VM KA, NF Fernandez, Roux G. Incidence of thyroid cancer in patients of the city of Corrientes. Cat Rev Med VI Postgrad. 2007;175(1):1-3.

16. Tuttle RM, DW Ball, D. Thyroid carcinoma, version 2. Byrd J Natl Cancer Network Compr. 2010;12(12):1671-1680.

17. Dogs P, S Colley, Boelaert K, et al. Guidelines for the management of thyroid cancer. Clin Endocrinol (Oxf). 2014;81(Suppl 1):1-122.

18. Bilimoria KY, Bentrem DJ, Ko CY. Extent of surgery for papillary thyroid Affects cancer survival. Ann Surg. 2007;246(3):375-381.

19. Lucena Olavarrieta JR. Thyroid carcinoma. Results of surgical treatment. Venez Rev Oncol. 2005;17(2):129-134.

20. Vaisman F, Shaha A, S Fish, Michael R Tuttle. Initial Therapy With thyroid lobectomy or Either the total thyroidectomy without ablation is associated radioactiveiodine remnant With very low rates of recurrence structural disease in Patients With properly selected Differentiated thyroid cancer. Clin Endocrinol (Oxf). 2011;75(1):112-119.

21. KC Loh, Greenspan FS, Geel, et al. Pathological tumor-node-metastasis (pTNM) papillary and follicular staging for thyroid carcinomas: a retrospective analysis of 700 patients. J Endocrinol Metab Clin. 1997; 82(11):3553-3562.

22. Mazzaferri EL, Jhiang SM. Long-term impact of initial surgical and medical therapy on papillary and follicular thyroid cancer. Am $J$ Med. 1994; 97(5):418-428.

23. JL Refoyo pardal. Complications of thyroid surgery. Presentation at the XVIII Congress of the Society otolaryngology Cantabria Castilla y Leon and La Rioja Zamora. Rev Soc Otorrinolaringol Castilla y León Cantabria and La Rioja Zamora. 2010;1(4):1-152. 